J. Egypt. Soc. Parasitol. (JESP), 51(2), 2021: 365 - 370

(Online: 2090-2549)

\title{
SEROPREVALENCE OF TOXOPLASMA GONDII IN SCHIZOPHRENIC PATIENTS VERSUS HEALTHY INDIVIDUALS AND ITS POSSIBLE IMPACT ON HUMAN SERUM DOPAMINE LEVEL
}

\section{By}

SALWA M. MORSY ${ }^{1,2 *}$, MOUSA A. M. ISMAIL ${ }^{1}$ AND MARWA M. I. GHALLAB ${ }^{3}$ Department of Medical Parasitology, Faculty of Medicine, Cairo University ${ }^{1}$, and Faculty of Medicine, Modern University for Technology and Information ${ }^{2}$, Egypt and Department of Medical Parasitology, Faculty of Medicine, Kafrelsheikh University, Egypt $^{3}$ ( ${ }^{*}$ Correspondence: smmorsy@kasralainy.edu.eg)

\section{Abstract}

Several studies demonstrated a high seroprevalence of Toxoplasma gondii in schizophrenic patients than healthy individuals. This case control study determined the serprevalence of $T$. gondii among schizophrenic patients and healthy individuals at Kafrelsheikh University Hospitals and to estimate its effect on serum dopamine level. T. gondii IgG was detected in $52.2 \% \& 23.9 \%$ of schizophrenic patients and healthy individuals respectively with significance $(P$ value $=0.005)$. Serum dopamine level was higher in schizophrenic patients than healthy individuals with statistical significance $(P=<0.001)$ and also higher in $T$. gondii $\operatorname{IgG}$ positive than $T$. gondii $\operatorname{IgG}$ negative patients with statistical significance $(P=<0.001)$.

Key words: Toxoplasma gondii, Schizophrenic Non-schizophrenic, Dopamine level

\section{Introduction}

Toxoplasmosis is an infectious disease caused by a parasitic protozoan Toxoplasma gondii that affected about one third of world population (Flegr et al, 2014). It infects all species of mammals and numerous species of warm-blooded animals, but, human incidence varied according to demographic, hygienic and human factors (Jones et al, 2014).

Many health disorders and diseases were correlated with toxoplasmosis (Fuglewicz et $a l, 2017)$. A persistent dormant toxoplasmasis was involved in many neuro-psychiatric symptoms (Henriquez et al, 2009). They reported higher incidence of chronic toxoplasmosis in patients suffered from various psychiatric disorders (Torrey et al, 2007).

Schizophrenia is a severe psychiatric disorder affected about $1 \%$ of population as the $9^{\text {th }}$ most common cause of disability worldwide (Torrey et al, 2012). It is manifested by the hallucinations, delusions, disturbances in thinking \& communication and main substances responsible for such symptoms were dopamine, serotonin, GABA, and glutamate (Ali et al, 2020). The clinical picture onset typically occurred between the late teens and early 30 s, with the peak incidence occurring in males in the early to mid-twenties, and in females in the late twenties (Ferri, 2019). Schizophrenia is characterized by continuous or relapsing episodes of psychosis (Owen et al, 2016). It was described as a neurodevelopmental feature without precise boundary, or a cause, developed from gene-environment interactions with involved vulnerability factors (Davis et al, 2016), or environmental infectious agent factors (Fuglewicz et $a l, 2017)$. One cause in the schizophrenia context was $T$. gondii (Xiao et al, 2018). Exposure to pet cats during infancy and childhood was associated with altered rates of psychiatric disorders development as schizophrenia and bipolar disorder in later life (Yolken et al, 2019). Several mechanisms by $T$. gondii achieved this behavioral in the host, as influencing the neurotransmitters levels in the intermediate hosts' brain (Elsheikha et $a l, 2016)$, by increasing dopamine release in neurons, probably by self-expression of genes encoding enzyme responsible for dopamine synthesis (McFarland et al, 2018). Toxoplasmosis altered glutamate signaling in brain (David et al, 2016). Also, the immunological pathway was another possible mechanism when pro-inflammatory cytokines associated with toxoplasmosis induced apoptosis that led to neurodegeneration (Sutterland 
et al, 2020). Such mechanisms have important role in psychotic disorders, as neurotransmitters and immunological disturbances attributed to psychosis and schizophrenia pathophysiology (Al-Diwani et al, 2019).

Diagnosis of toxoplasmosis depends on serological tests as ELISA that detected $T$. gondii-specific IgG \& IgM antibodies. An IgG titer cannot differentiate recent from past infection but may be considered as a confirmation for exposure to the infection while IgM antibodies were detected earlier than IgG antibodies and decrease faster, but they didn't indicate acute infection as they could remain for years after acute infection without clinical value (Ekici et al, 2021).

This study aimed at serological diagnosis of toxoplasmosis in relation to schizophrenia and estimation of its effect on human serum dopamine level.

\section{Materials and Methods}

Study design and population: A cross-sectional study was conducted on 92 individuals; 46 patients aged 19-45 schizophrenia diagnosed and followed-up at outpatient clinic of Neuropyschiatry Department, Kafrelsheikh University Hospitals all over the year 2020 (case group) and cross-matched 46 healthy individuals without schizophrenia were included as a control group. A pre-designed questionnaire was used to collect demographic and clinical data of all subjects.

Work plan: Serum samples were collected from each participant (case and control) and subjected to: 1- Anti-Toxoplasma IgG antibodies detection by using Nova-Lisa Toxoplama IgG-ELISA (Nova Tec-Immundiagnostica GmbH, D-63128 Dietzenbach, Germany). Results were interpreted and reactive when $\mathrm{IgG}$ index was at $>35 \mathrm{IU} / \mathrm{ml}$, equivocal at 30 $-35 \mathrm{IU} / \mathrm{ml}$ and non-reactive at $<30 \mathrm{IU} / \mathrm{ml}$. 3Anti-Toxoplasma IgM antibodies detection by IgM-capture ELISA (DRG ${ }^{\circledR}$ Toxoplasma IgM, TORCH, EIA1799, DRG International, Inc., USA). Results were interpreted as negative when $\operatorname{IgM}$ index at $<0.9$, equivocal at 0.9 to 1.0 , while positive if IgM index was at $>$ or equal to 1.0. 3- Human serum Dopa- mine level was detected by using human dopamine ELISA kit $\left(\mathrm{DRG}^{\circledR}\right.$ Dopamine EIA4161, DRG ${ }^{\circledR}$ International, Inc., USA) according to manufacturer's protocol. Solution absorbance in wells was read within 10 minutes by a microplate reader set to $450 \mathrm{~nm}$ and a reference wave-length between $620 \mathrm{~nm} \&$ $650 \mathrm{~nm}$. Plasma concentration samples were divided by 60 .

Statistical analysis: Data were coded and entered using statistical package for Social Sciences (SPSS) version 26 (IBM Corp., Armonk, NY, USA). Data was summarized as mean, standard deviation, median, minimum, \& maximum in quantitative data and using frequency (count) and relative frequency (percentage) for categorical data. Comparisons between quantitative variables were done by non-parametric Mann-Whitney test (Chan, 2003a). For comparing categorical data, Chi square $\left(\chi^{2}\right)$ test was used. Exact test was used instead when the expected frequency was less than 5 (Chan, 2003b). Pless than 0.05 were considered significant.

\section{Results}

This cross-sectional study was done on 92 subjects divided into two groups: schizophrenic group (46 patients) and healthy individuals group (46 individuals). Schizophrenic group was 36 males \& 10 females with mean age of $30.9+/-8.9$, and healthy ones were 34 males and 12 females with mean age of $30.7+/-7.9$. Cat exposure was high in schizophrenic patients $(19.6 \%)$ than healthy ones $(6.5 \%)$ without significance $(P=0.063)$, but raw meat consumption was a risk factor with high level in schizophrenic patients (54.3\%) than healthy ones $(6.5 \%)$ with significance $(P<0.001)$.

Psychotic disorders among patients and controls were behavioral and personality changes, increased activity, hallucinations and suicidal attempts were significance among schizophrenia ones.

T. gondii IgM was $10.9 \% \& 17.4 \%$ in schizophrenic patients and healthy ones respectively without significance, $T$. gondii IgG was $52.2 \% \& 23.9 \%$ in schizophrenic patie- 
nts and healthy ones respectively with significance between schizophrenia and IgG positive ones $(P$ 0.005), but no significant was between schizophrenia \& IgM positivity $(P$ $0.369)$. Dopamine mean level was higher in schizophrenic patients $(89.15+/-18.73)$ than healthy ones $(32.30+/-20.39)$ and the relation between schizophrenia and serum dopa- mine level was significant $(P<0.001)$. Dopamine serum levels were paralleled in $T$. gondii $\mathrm{IgG}$ positive and $T$. gondii $\mathrm{IgG}$ negative patients and showed higher level in $T$. gondii $\operatorname{IgG}$ positive $(92.32+/-20.61)$ than $T$. gondii IgG negative $(41.33+/-26.06)$ with statistical significance $(P<0.001)$.

Details were given in tables $(1,2, \& 3)$.

Table 1: Demographic and clinical data of population

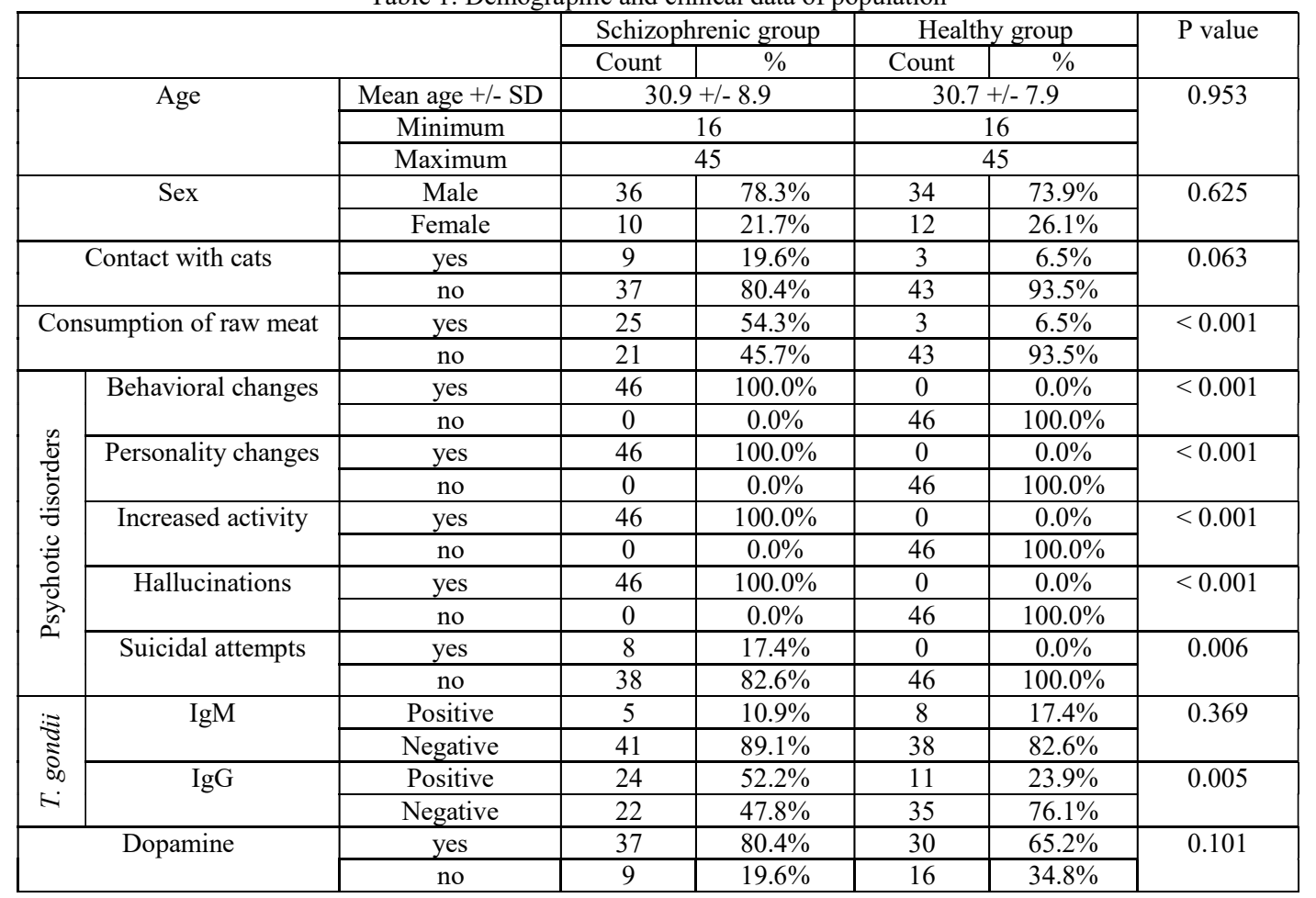

Table 2: Relation of schizophrenia and serum dopamine level

\begin{tabular}{|c|c|c|c|c|c|c|c|c|c|}
\hline \multirow[t]{2}{*}{ Dopamine } & \multicolumn{4}{|c|}{ Schizophrenic patients } & \multicolumn{4}{|c|}{ Healthy individuals } & \multirow[t]{2}{*}{ P value } \\
\hline & $\mathrm{M} \pm \mathrm{SD}$ & Median & Minimum & Maximum & $\mathrm{M} \pm \mathrm{SD}$ & Median & Minimum & Maximum & \\
\hline $\mathrm{pg} / \mathrm{ml}$ & $89.15 \pm 18.73$ & 88.50 & 60.00 & 120.00 & $32.30 \pm 20.39$ & 24.00 & 11.00 & 84.00 & $<0.001$ \\
\hline
\end{tabular}

Table 3: Relation of $T$. gondii IgG positivity and serum dopamine level

\begin{tabular}{|c|c|c|c|c|c|c|c|c|c|}
\hline \multirow{2}{*}{ Dopamine } & \multicolumn{4}{|c|}{ IgG positive } & \multicolumn{4}{c|}{ IgG negative } & P value \\
\cline { 2 - 10 } & $\mathrm{M} \pm \mathrm{SD}$ & Median & Minimum & Maximum & $\mathrm{M} \pm \mathrm{SD}$ & Median & Minimum & Maximum & \\
\hline $\mathrm{pg} / \mathrm{ml}$ & $92.31 \pm 20.61$ & 97.00 & 55.00 & 120.00 & $41.33 \pm 26.06$ & 26.00 & 11.00 & 90.00 & $<0.001$ \\
\hline
\end{tabular}

\section{Discussion}

One of the main associations between toxoplasmosis and development of psychiatric disorders was schizophrenia (Fekadu et al, 2010)

In the present study, schizophrenia patients showed a higher $T$. gondii antibodies level to than in controls. This agreed with El-Sayed et al. (2012) who found that toxoplasmosis patients developed psychotic symptoms as delusions and hallucinations-like those of sc- hizophrenia, with elevated dopamine levels in experimentally infected animals and schizophrenic patients. T. gondii seroprevalence of up to $85 \%$ was among tropic populations in the developing countries (Hernández-Cortazar et al, 2015; Nayeri et al, 2020).

In Egypt, Wishahy et al. (1975) reported congenital toxoplasmosis in children with some neurological manifestations. Rifaat et al. (1975) reported infantile toxoplasmosis \& some neurological disorders. Rifaat et al. 
(1981) reported T. gondii seropositivity in stray cats. Mabrouk and Dahawi (1991) found that 42 meningoencephalitis patients with negative C.S.F. cultures for commonest pathogenic showed 10/42 (26\%) positive IIFA Toxoplasma IgG antibodies. They added that clinical presentation \& C.S.F changes with high antibody titers incriminated toxoplasmosis to be the etiologic agent. Al-Kappany et al. (2010) reported that high prevalence of $T$. gondii in feral cats indicated a high oocysts environmental contamination. Saleh et al. (2014) found T. gondii infection among childbearing age females. Abdel Rahman et al. (2016) found protozoa parasites as T. gondii, Babesia species and Plassmodium falciparum in patients with aseptic meningitis. Abbas et al. (2020) reported that toxoplasmosis was highly prevalent in man and animals from rural Egypt where life circumstances favor for $T$. gondii transmission.

In the present study, high $T$. gondii IgG positivity $(52.2 \%)$ was in schizophrenic patients than in controls $(23.9 \%)$. This agreed with Ali et al. (2020) who reported higher $T$. gondii seroprevalence in Egyptian Schizophrenic patients $(55.6 \%)$ than healthy persons (28.9\%). Mortensen et al. (2007) in Denmark reported that early exposure to several infectious agents was associated with later schizophrenia development. They added that the causal linking mechanisms were the present speculative but with possible direct effects of maternal $T$. gondii IgG on the developing CNS of the offspring

Dogruman et al. (2009) in Turkey found a rate of $47.7 \%$ and $21.6 \%$ in schizophrenic patients and healthy persons, respectively, and added that $T$. gondii played a role in pathogenesis of some schizophrenia patients. Morsy et al. (1978) in Jordan found that congenital toxoplasmosis was the main cause among mentally retarded children. Tanyüksel et al. (2010) in Turkey reported T. gondii sero-positivity was $43.8 \%$ in schizophrenic patients and $32.5 \%$ in healthy ones. Yagmur et al. (2010) in Turkey detected toxoplasmaosis as cause of attempted suicide (41\%) ve- rsus $(28 \%)$ in control ones. But, Arling et al. (2009) in USA neither found significant relation between $T$. gondii seropositivity or the suicide attempt status, number of prior suicide attempts, nor recurrent diagnosed mood disorder. They added that although preliminary and bearing replication, this was the first report, to their knowledge, of an association between attempting suicide and toxoplasmasis infection.

In the present study, $T$. gondii IgM didn't show significantly different between $10.9 \%$ \& $8.7 \%$ in the schizophrenic patients and healthy ones, respectively. No doubt, IgM is the marker of infection, which became negative within 4-12 weeks, and thus no schizophrenia significance. Also, Hamidinejat et al. (2010) in Iran didn't find associations between immune status ratio values and the schizophrenia risk, but Juanah et al. (2013) in Malaysia found a marked relationship between toxoplasmosis and schizophrenia.

The schizophrenic patients with toxoplasmosis showed different serum dopamine levels (Flegr et al, 2003). Also, the increased dopamine levels in the seropositive schizophrenic cases compared to seronegative schizophrenic cases was accountable for the behavioral changes (Mahmoudvand et al, 2015). Ali et al. (2020) reported that the behavioral changes in the $T$. gondii seropositive patients were related to increase in the serum dopamine level. This neurotransmitter played the noteworthy role in schizophrenia (Hodková et al, 2007). Prandovszky et al. (2011) found that serum dopamine increase levels to risk deterioration of schizophrenia.

\section{Conclusion}

The outcome data may suggest an association between toxoplasmosis infection and schizophrenia.

Nevertheless, efforts must be directed to toxoplasmosis prevention by the health education and arising awareness of its risk factors as to the stray and/or pet cats, eating habits especially of raw vegetables and fruits, hand-washing and hygienic behavior.

Conflict of Interest: Authors declared that 
they neither have interest nor received fund.

\section{References}

Abbas, IE, Villena, I, Dubey, JP, 2020: A review on toxoplasmosis in humans and animals from Egypt. Parasitology 147, 2:135-59.

Abdelrahman, RZ, Morsy, ATA, Morsy, T A, 2016: Aseptic meningitis in adults causing by virus, bacteria, drug with special references to zoonotic parasites. J. Egypt. Soc. Parasitol. 46 2:329-50.

Al-Diwani, A, Handel, A, Townsend, L, Pollak, T, Leite, MI, et al, 2019: The psycho-pathology of NMDAR-antibody encephalitis in adults: A systematic review and phenotypic analysis of individual patient data. Lancet Psychiat. 6, 3:235-46.

Al-Kappany, YM, Rajendran, C, Ferreira, L R, Kwok, OC, Abu-Elwafa, SA, et al, 2010: High prevalence of toxoplasmosis in cats from Egypt: Isolation of viable Toxoplasma gondii, tissue distribution, and isolate designation. J. Parasitol. 96, 6:1115-8.

Ali, MI, Ismail, MAM, Abd-Allah, GA, Abdel-Latif, M, Shaapan, RM, et al, 2020: Toxoplasmosis in schizophrenic patients: Immunediagnosis and serum dopamine level. Pak. J. Biol. Sci. 23. https://www.researchgate.net/publication/343126915

Arling TA, Yolken RH, Lapidus M, Langenberg P, Dickerson FB, et al, 2009: Toxoplasma gondii antibody titers and history of suicide attempts in patients with recurrent mood disorders. J. Nerv. Ment. Dis. 197, 12:905-8.

Chan, YH, 2003a: Biostatistics102: Quantitative data, parametric \& non-parametric tests. Singapore Med. J. 44, 8:391-6.

Chan, YH, 2003b: Biostatistics 103: Qualitative data, tests of independence. Singapore Med. J. 44, 10:498-503.

David CN, Frias ES, Szu JI, et al, 2016: GLT1-dependent disruption of CNS glutamate homeostasis and neuronal function by the protozoan parasite Toxoplasma gondii. PLoS Pathol. 12, 6:e1005643.

Davis, J, Eyre, H, Jacka, FN, et al, 2016: A review of vulnerability and risks for schizophrenia: Beyond the two hit hypothesis. Neurosci. Biobehav. Rev. 65:185-94.

Dogruman-AI, F, Aslan S, Yalcin, S, Kustimur, S, Turk, S, 2009: A possible relationship between Toxoplasma gondii and schizophrenia: A seroprevalence study. Int. J. Psychiat. Clin.
Pract. 13, 1:82-7.

Ekici, A, Timuçin, DK, Gürbüz, E, Ünlü, AH, Aydemir, S, et al, 2021: Investigation of the relationship between schizophrenia and toxoplasmosis in Van Province, Turkey, PUJ. 14, 1:34-8. El-Sayed, NM, Ismail, KA, Ahmed, SA, EzzEl-Din, HM, Azzam, HME, 2012: Possible association between Toxoplasma gondii infection and schizophrenia. Infect Dis. Clin. Pract. 20, 6:394-9.

Elsheikha, HM, Büsselberg, ZD, Zhu, XQ, 2016: The known and missing links between Toxoplasma gondii and schizophrenia. Metab. Brain Dis. 31, 4:749-59.

Fekadu, A, Shibre, T, Cleare, AJ, 2010: Toxoplasmosis as a cause for behavior disorders overview of evidence and mechanisms. Folia Parasitol. 57, 2:Y105-13.

Ferri, FF, 2019: Ferri's Clinical Advisor: 5 Books in 1.

Flegr, J, Prandota, J, Sovickova, M, Israili, Z F, 2014: Toxoplasmosis, a global threat: Correlation of latent toxoplasmosis with specific disease burden in a set of 88 countries. PLoS One 9: e90203.

Flegr, J, Preiss, M, Klose, J, Havlicek, J, Vitakova, M, 2003: Decreased level of psychobiological factor novelty seeking and lower intelligence in men latently infected with the protozoan parasite Toxoplasma gondii dopamine, a missing link between schizophrenia and toxoplasmosis? Biol. Psychol. 63:253-68.

Fuglewicz, A, Piotrowski, P, Stodolak, A, 2017: Toxoplasma gondii and psychiatric disorders, Adv. Clin. Exp. Med. 26, 6:1031-6.

Gaskell, EA, Smith, JE, Pinney, JW, Westhead, DR, McConkey, GA, 2009: A unique dual activity amino acid hydroxylase in Toxoplasma gondii. PLOS One 4: Pages

Hamidinejat, H, Ghorbanpoor, M, Hosseini, H, Alavi, SM, Nabavi L, et al, 2010: Toxoplasma gondii infection in first-episode and inpatient individuals with schizophrenia. Inter. J. Infect. Dis. 14:e978-81.

Henriquez, SA, Brett, R, Alexander, J, Pratt, J, Roberts, CW, 2009: Neuropsychiatric disease and Toxoplasma gondii infection. Neuroimmunomodulation 16:122-33.

Hernández-Cortazar, I, Acosta-Viana, KY, Ortega-Pacheco, A, et al, 2015: Toxoplasmosis in Mexico: Epidemiological situation in humans and animals. Rev. Inst. Med. Trop. SP. 57, 2:93103. 
Hodková, H, Kodym, P, Flegr, J, 2007: Poorer results of mice with latent toxoplasmosis in learning tests: Impaired learning processes or the novelty discrimination mechanism? Parasitology 134:1329-37

Jones, JL, Parise, ME, Fiore, AE, 2014: Neglected parasitic infections in the USA: Toxopasmosis. Am. J. Trop. Med. Hyg. 90:794-9.

Juanah, LY, Jalaludin, J, Osman, M, Osman, ZJ, 2013: Seroprevalence of Toxoplasma gondii among schizophrenics at Hospital Kajan. Am. J. Infect. Dis. 9, 1:11-6.

Mabrouk, MA, Dahawi, HS, 1991: Toxoplasma antibodies in patients with meningoencephalitis. J. Egypt. Soc. Parasitol. 21, 2:547-51.

Mahmoudvand, H, Ziaali, N, Aghaei, I, Sheibani, V, Shojaee, S, et al, 2015: The possible association between Toxoplasma gondii infection and risk of anxiety and cognitive disorders in BALB/c mice. Pathol. Glob. Hlth. 109: 369-76.

McFarland, R, Wang, ZT, Jouroukhin, Y, et al, 2018: AAH2 gene is not required for dopamine-dependent neurochemical and behavioral abnormalities produced by Toxoplasma infection in mouse. Behav. Brain Res. 347:193-200.

Morsy, TA, El Dasouqi, STY, Michael, SA, 1978: Toxoplasmin skin tests in mentally retarded children in Jordan. $11^{\text {th }}$ Middle Eastern Medical Pediatric Congress, Marseille, France. Mortensen, PB, Pedersen, B, Waltoft, BL, Sorensen, TL, Hougaard, D, et al, 2007: Early infections of Toxoplasma gondii and the later development of schizophrenia. Schizophr. Bull. 33, 3:741-4.

Nayeri, T, Sarvi, S, Moosazadeh, M, et al, 2020: The global seroprevalence of anti-Toxoplasma gondii antibodies in women who had spontaneous abortion: A systematic review \& metaanalysis. PLoS Negl. Trop. Dis. 14, 3:e008103.

Owen, MJ, Sawa, A, Mortensen, PB, 2016: Schizophrenia. Lancet 388, 10039:860-97.

Prandovszky, E, Gaskell, E, Martin, H, Dubey, JP, Webster, P, et al, 2011: The neurotropic parasite Toxoplasma gondii increases dopamine metabolism. PLoS One 6: e23866.

Rifaat, MA, Wishahy, AO, Morsy, TA, Sadek, MSM, Hussein, D, 1975: Toxoplasmosis and some neurological disorders in Egypt. J. Egypt. Pub. Hlth. Assoc. 50, 1:1-10.

Rifaat, MA, Morsy, TA, Sadek, MSM, Mahmoud, AMK, 1981: Antibodies against some parasites in stray cats in Cairo. J. Egypt. Soc.
Parasitol. 11, 2:517-24.

Saleh, AMA, Ali, HA, Ahmed, SAM, Hosny, SM, Morsy, TA, 2014: Screening of Toxoplasma gondii infection among childbearing age females and assessment of nurses' role in prevention and control of toxoplasmosis. J. Egypt. Soc. Parasitol. 44, 2:329-42.

Sutterland, AL, Mounir, DA, Ribbens, JJ, Kuiper, B, Gool, TV, et al, 2020: Toxoplasma gondii infection and clinical characteristics of patients with schizophrenia: A systematic review and meta-analysis. Schizophr. Bull. Open, http://creativecommons.org/licenses/by-nc/4.0/

Tanyüksel, M, Uzun, Ö, Araz, E, Koruc, Ö, Babür, C, 2010: Possible role of toxoplasmosis in patients with first-episode schizophrenia. Turk. J. Med. Sci. 40, 3:399-404.

Teimouri, A, Mohtasebi, S, Kazemirad, E, Keshavarz, H, 2020: Role of Toxoplasma gondii $\operatorname{IgG}$ avidity testing in discriminating between acute and chronic toxoplasmosis in pregnancy. J. Clin. Microbiol. 58, 9:e00505-20.

Torrey, EF, Bartko, JJ, Lun, ZR, Yolken, RH, 2007: Antibodies to Toxoplasma gondii in patients with schizophrenia: A meta-analysis. Schizophr. Bull.33:729-36.

Torrey, EF, Bartko, JJ, Yolken, RH, 2012: Toxoplasma gondii and other risk factors for schizophrenia: An update. Schizophr. Bull. 38: 642-7.

Wishahy, AO, Rifaat, MA, Morsy, TA, EI Naggar, BA, 1975: Toxoplasmosis in children with some neurological manifestations. J. Trop. Med. Hyg. 75, 12:255-6.

Xiao, J, Prandovszky, E, Kannan, G, Pletnikov, MV, Dickerson, F, et al, 2018: Toxoplasma gondii: Biological parameters of the connection to schizophrenia. Schizophr. Bull. 44, 5:98392.

Yagmur, F, Yazar, S, Temel, HO, Cavusoglu, M, 2010: May Toxoplasma gondii increase suicide attempt preliminary results in Turkish subjects? Forens. Sci. Int. 199, 1/3:15-7.

Yolken, RH, Dickerson, FB, Fuller Torrey, E, 2009: Review: Toxoplasma and schizophrenia. Parasite Immunol. 31:Y706-14.

Yolken, R, Stallings, C, Origoni, A, Katsafanas, E, Sweeney, K, et al, 2019: Exposure to household pet cats and dogs in childhood \& risk of subsequent diagnosis of schizophrenia or bipolar disorder. PLoS One 2019 14, 12: e0225320 